\title{
A Quasi-Experimental Intervention to Improve Self-Efficacy for Eating and Exercise Weight Management: Short-Term Effects
}

Regina Lee LT*$^{*}$ and Alice Yuen Loke

School of Nursing, The Hong Kong Polytechnic University, Hung Hom, Hong Kong

\begin{abstract}
Aims: To determine the effects of a nutrition and exercise weight management program supported by social cognitive theory on self-efficacy, body mass index and psychosocial functioning in adolescents aged 10-13 years $(n=119)$.

Methods: A quasi-experimental intervention to improve self-efficacy for eating and exercise weight management for 59 overweight adolescents aged 10-12 years who participated in a 6-month weight-control self-efficacy programme. The control group consisted of 60 overweight adolescents. The changes in BMI, lifestyles and psychosocial functioning through self-efficacy beliefs, were assessed using the chi-squared and $t$-test.

Results: Weight loss at 6 months was 0.05 kilograms of baseline body weight, and self-efficacy scores increased in the range of 0.58 to 0.75 among adolescents in the intervention group, while for those in the control group, self-efficacy scores decreased by -0.15 to -1.03 . Self-esteem was one of the psychosocial factors that caused the overweight and obese adolescents to eat appropriately and intend to exercise regularly. Thus, this intervention had the most significant impact on adolescents' self-esteem $(t=3.2, p=0.002)$ using the paired $t$-test between the pre- and post-tests.

Conclusions: Findings were consistent with the social cognitive theory, namely that improvement in self-efficacy over time supports greater weight loss. Adherence to exercise and appropriate eating can benefit weight-loss outcomes because individuals' cognitive capability and belief in the intervention are taken into consideration by engaging them in pre-set actions and health outcomes.
\end{abstract}

Keywords: Obesity; Self-efficacy; Chinese adolescents; Intervention; Psychosocial functioning

\section{Background}

Overweight and obesity are the nation's fastest rising public health concern and have become a top priority in both Hong Kong and Taiwan, which had prevalence rates of $21.7 \%$ and $16 \%$ respectively in 2010 [1]. Adequate exercise and healthy eating have an important role to play in the prevention of child and adolescent obesity. School-based interventions struggle to achieve meaningful and lasting effects on the adoption of healthy lifestyle behaviors [2]. It has been reported that the effects of the conventional approach, with the single goal of adolescent weight loss, are the subject of debate [3]. Theorists have suggested that this may be due to the failure to incorporate psychosocial mediators as they relate to behavior change $[4,5]$.

There is strong evidence suggesting that alternative interventions focusing on social cognitive variables and incorporating psychosocial mediators such as self-efficacy for behavioral maintenance are effective [6-8]. However, very few studies have focused on the impact of selfefficacy on the effectiveness of lifestyle modification for overweight adolescents [9-11]. Thus, it is critical to examine the role of selfefficacy as the psychosocial mediator, with the intention of assisting individuals in preventing weight gain, optimizing individual weight loss interventions, and achieving long-term weight loss maintenance.

Despite an increasing number of publications on childhood obesity in Western countries over the past decade [12-14], similar information regarding the Hong Kong population is scarce. Nevertheless, no study has measured Hong Kong adolescents' self-efficacy and intention to practice healthy lifestyle behaviors, or assessed its potential influences in initiating behavior change. Public health policies and protocols have increasingly recognized the importance of a higher level of scope in enabling actions as an essential component to programs and settingsbased initiatives in addressing these public health problems [15].

Social cognitive theory explains how an individual acquires and maintains certain behavioral patterns, and it also provides the basis for intervention strategies [16]. This study followed a cohort of 10- to 13-year-olds who was identified as overweight or obese. Its aim was to examine the impact of social cognitive theory in the association between self-regulatory weight management interventions and selfefficacy beliefs in their ability to increase their motivation and intention to exercise and eat appropriately for 6 months.

\section{Methods}

The self-efficacy weight management intervention in this study was planned and delivered to 59 overweight and obese adolescents aged 1013 (one dropped out after starting the interventions) for 6 months in two selected primary schools in Hong Kong. The intervention group benefited from self-regulatory interventions including daily selfweighing make a declaration of how much weight they wanted to lose, a weekly dietary log sheet, monthly dietary consultation sessions, daily planned physical activity lessons, regular group gathering and sharing sessions with a reward system, and monthly behavioral counseling sessions based on the self-reported weekly dietary log book.

The study was conducted in four primary schools in Tsing Yi Island in Hong Kong. Tsing Yi Island, located in the northwest of Hong Kong, is inhabited by a low socio-economic class including a dense population

*Corresponding author: Regina Lee, School of Nursing, The Hong Kong Polytechnic University, Hung Hom, Kowloon, Hong Kong, E-mail: Regina.Lee@polyu.edu.hk

Received October 18, 2012; Accepted November 22, 2012; Published November 24, 2012

Citation: Regina Lee LT, Loke AY (2013) A Quasi-Experimental Intervention to Improve Self-Efficacy for Eating and Exercise Weight Management: Short-Term Effects. J Nutr Disorders Ther 3:121. doi:10.4172/2161-0509.1000121

Copyright: ( 2013 Regina Lee LT, et al. This is an open-access article distributed under the terms of the Creative Commons Attribution License, which permits unrestricted use, distribution, and reproduction in any medium, provided the original author and source are credited. 
of new immigrants from mainland China. The four schools had 200700 primary school students aged 6-13 from primary one to primary six (P.1-6) during the period of data collection. The study was conducted over a period of eight months in 2009. This period was chosen to identify the usual pattern of primary school students' health practices by avoiding seasonal holidays and stressful periods such as examination time. Primary four to primary six (P.4-6) school students whose body weight was over the $85^{\text {th }}$ percentile and whose parents allowed them to participate in the self-efficacy beliefs weight management program were recruited from the four selected primary schools to join the study. Prior consents were obtained from the parents of the primary school students via the school before the commencement of the study. The health education and P.E. teachers helped with the distribution and collection of the questionnaires in each school.

\section{Intervention}

The self-regulatory weight loss intervention was a community collaborative project using an interdisciplinary approach including university academic staff, school teachers (health education and physical exercise teachers), and a nutritionist. The intervention helped children in the two selected schools to adopt and sustain healthier lifestyles by enhancing awareness, changing behaviours or creating an environment that supports good health practices earlier in their early adolescence in the school settings. Helping adolescents to establish healthy lifestyles and avoid developing health risk behaviours is crucial and should be started before these behaviours are firmly established. The project team has developed a self-regulatory weight management program in collaboration with university academic staff, paediatric consultant, school nurses, school principals, school teachers and parents to support the physical, mental, emotional, behavioural and social well-being of overweight and obese adolescents. The project also enjoyed the partnership of non-governmental organizations with the similar aim of developing healthy adolescents who are capable of being successful learners.

For overweight and obese adolescents in the intervention group, a nutritionist with experience and education in dietetics and nutrition worked with the school food services to guide the progress toward achieving their goals over time. The nutritionist also provided consultation for the design of health education talks related to healthy eating (smart food choices, fewer added sugar beverages, more water intake, a healthy kitchen, awareness of the broader benefits of a variety of food choices, and the synergy between physical activity and food choices). The nutritionist continued to provide guidance to food providers, delivered nutritional talks to parents and expanded the food and nutrition messages by designing a series of group activities (one per month for a total of 10 sessions) to increase their knowledge, enhance their decision-making skills, promote peer involvement and interaction in the sharing session and support group, and enhance social influence.

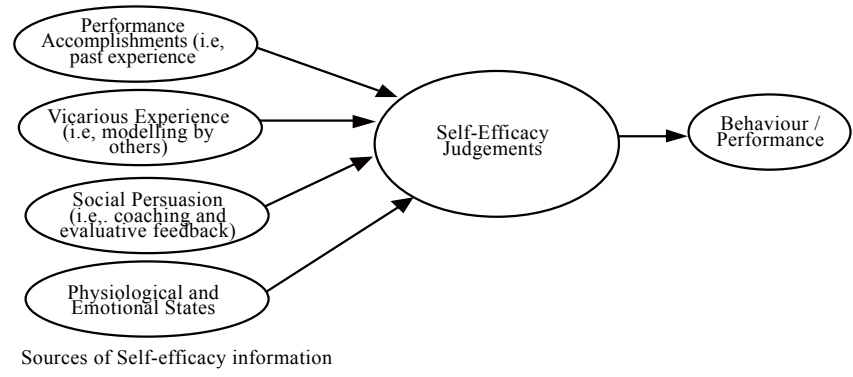

Figure 1: Diagram to explain the Self-efficacy Theory in this study.
People tend to avoid activities that they believe exceed their coping capabilities, but they readily undertake activities and select social environments they judge themselves capable of handling.

A school nurse was also involved in classroom activities related to promoting healthy lifestyles. The nutritionist and school nurse were in charge of answering questions related to diet control and the exercise program. Social skills for interpersonal relationships and psychological counseling due to weight control and body image change were also provided as part of the classroom activity. Various play activities and games were designed to encourage interactive sharing; positive feedback and reward systems were also provided to enhance self-efficacy as shown in figure 1. For example, adolescents learned how to select healthy meals and got involved in practice sessions about options and choices related to low-sugar and low-fat foods. In addition, each adolescent was also encouraged before the interventions to set realistic goals to help improve their dietary behavior and physical activity levels; they then wrote these down and sealed them in an envelope. The submission of the weekly dietary log book and participation in the daily after-school planned physical activity served as a tracking system to monitor each adolescent's progress. The log book enabled the researchers to track the frequency and usage duration of different sessions. These would be used in future analyses to validate the relations between self-regulatory skills and changes in self-efficacy after the expected behavioral change.

The individual and group behavior change initiatives aimed to promote the adoption of healthy behaviors and incorporate them into various behavior modification strategies: self monitoring, goal setting, group competition, and reinforcement through social recognition and rewards. Self monitoring and goal setting occurred throughout in order to reinforce and encourage adolescents to learn self-regulatory skills that are essential for behaviour change in social environments. During each social activity, the adolescents were asked to refer back to prior goal-setting and self-monitoring activities so as to reinforce these skills and foster repeated practice. Targeted behaviors were reinforced by a special recognition and reward system during regular gatherings in the support group.

\section{Design}

A quasi-experimental study design was adopted, with an intervention group and a control group with pre- and post-tests using the Chinese versions of the following scales: Weight Efficacy Lifestyle Scale, Nutritional Self-efficacy Scale, Exercise Self-efficacy Scales, Psychosocial Functional Domain, Adolescent Lifestyle Questionnaire and Body Shape Scale. Figure 2 shows the data collection procedure from the four primary schools in a suburban area of Hong Kong from which students were recruited and assigned to intervention and control groups.

Anthropometric measurements included height $(\mathrm{m})$, weight $(\mathrm{kg})$ and blood pressure ( $\mathrm{mmHg}$ ). Questionnaires were distributed to all adolescents $(\mathrm{N}=120)$ who attended the school in Primary 4-6. There were 119 questionnaires that were completed and returned, as one participant dropped out of the intervention group. As a result, 119 (response rate 99.1\%) questionnaires were analysed for this study. Altogether we recruited 119 overweight $\left(\mathrm{BMI} \geq 85^{\text {th }}\right.$ to $94^{\text {th }}$ percentile of age) and obese adolescents (BMI $\geq 95$ th percentile of age) studying in Primary 4-6 and aged 10-13, with BMI at or above the $85^{\text {th }}$ percentile. They were recruited equally from the four participating primary schools, with 30 from each school. Thus 59 overweight and obese adolescents from two of the primary schools were assigned to attend the 6-month efficacy-enhancing weight loss intervention. The 60 overweight and obese adolescents in the other two primary schools were assigned as the 


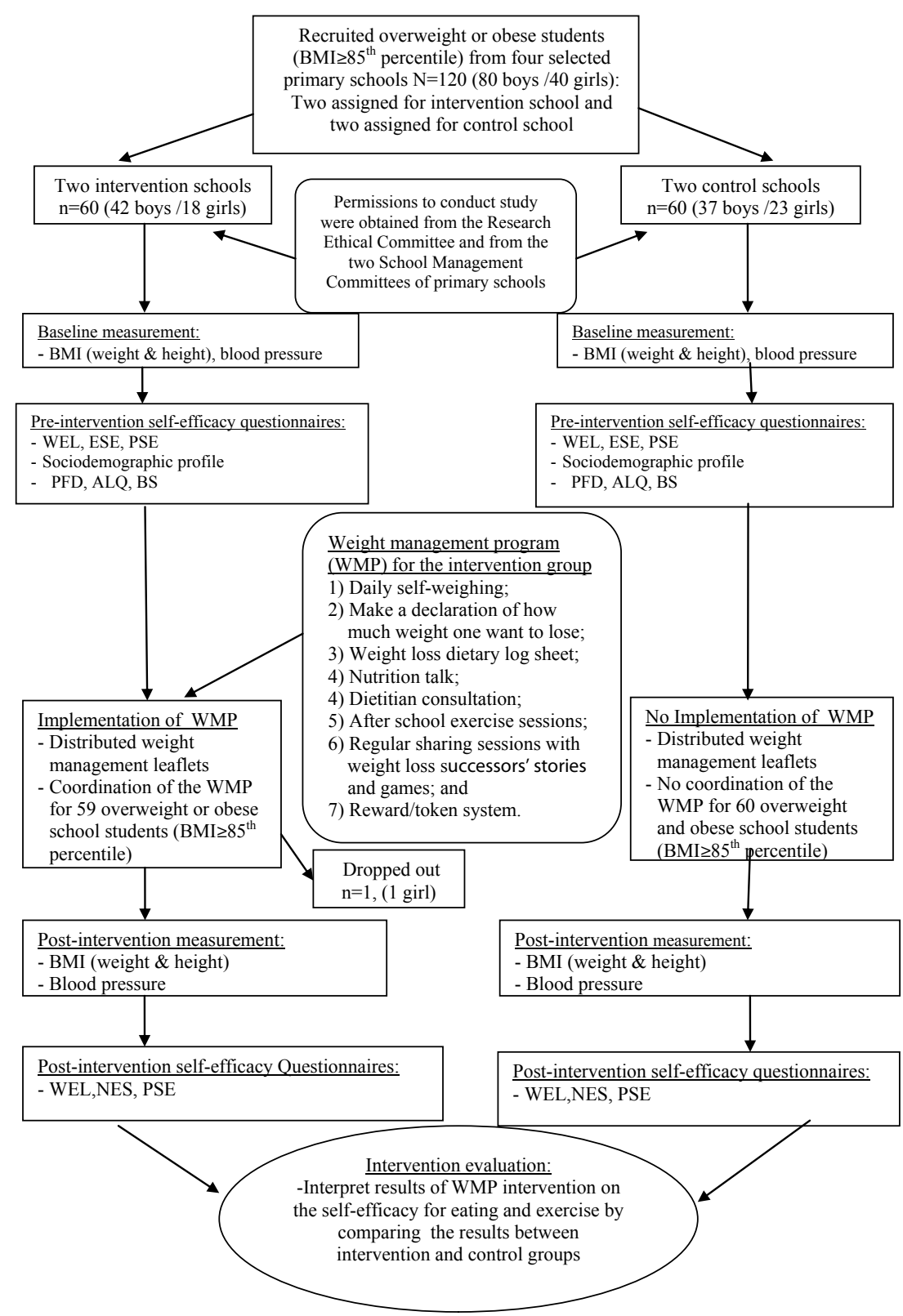

Figure 2: Measure self-efficacy for eating and exercise for the intervention group: A eight-month weight management program.

control group and received a leaflet on weight management. Baseline measurements including weight, height, body mass index and blood pressure were collected from eachadolescent. Data were computed with descriptive statistics, chi-squared and t-test based on their responses to the scales.

\section{Measures}

Weight Efficacy Lifestyle Questionnaire (WELQ): The Chinese version of the Modified Weight Efficacy Lifestyle Questionnaire (WELQ) is used to determine the adolescent's self-efficacy beliefs in weight loss interventions in the Chinese population, and its validity and reliability were tested and demonstrated good internal consistency in the sample (Cronbach's coefficient $\alpha=0.80,0.87$ and 0.88 respectively) [17]. The respondents rate their confidence in their ability to resist eating in certain situations on a 4-point Likert scale ranging from 0 (not confident) to 3 (very confident). There are 14 items: negative emotions, availability of foods, social pressure, physical discomfort, and positive activities. For example, item No. 5 is 'I can resist eating when I am watching TV'.

Nutrition Self-efficacy Scale (NES): The Nutrition Self-efficacy Scale (NES) is a health-specific self-efficacy scale used to examine the relationships between self-efficacy, intentions, and behaviours in the context of large field studies designed to screen diverse populations [18]. The NES consists of five items and uses a four-point Likert scale (1-4, with 1 indicating very certain, 2 rather uncertain, 3 rather certain, and 4 very certain) to measure each item. The Cronbach's alpha for the NES was 0.87 . For example, item No. 1 is 'I can manage to stick to healthful foods, even if I need a long time to develop the necessary routines.

Physical Exercise Self-efficacy Scale (PES): The Physical Exercise Self-efficacy Scale (PES) is another health-specific self-efficacy scale 
used to examine the relationships between self-efficacy, intentions and behaviours in the context of large field studies designed to screen diverse populations [18]. The PES consists of five items rated on a four-point Likert scale (1-4, with 1 indicating very certain, 2 rather uncertain, 3 rather certain, and 4 very certain) to measure each item. An individual is certain of carrying out their exercise intentions when they overcome these five particular barriers. The Cronbach's alpha for the PES was 0.88 . For example, item No.1 is 'I can manage to carry out my exercise intentions, even when I have worries and problems'.

Self-esteem Scale (SES): Rosenberg's Self-esteem Scale (SES) includes measures of self-reported self-esteem [19]. This self-report instrument is comprised of 10 items on a 5-point Likert scale, ranging from strongly agree to strongly disagree. The Cronbach's alpha for the SES was 0.75 . For example, item No. 1 is 'On the whole, I am satisfied with myself'.

Adolescent Lifestyle Questionnaire (ALQ): The Chinese version of the Adolescents' Lifestyle Questionnaire (C-ALQ) was developed and tested [20]. Adolescents were asked to indicate how often they adopted specific healthy lifestyle practices on a five-point Likert scale ranging from never (1) to rarely (2), sometimes (3), often (4) and almost always (5). The alpha reliability coefficient for the instrument was 0.91; alpha coefficients for the sub-scales ranged from 0.60-0.88. The 43-item C-ALQ consists of two constructs and seven dimensions: the healthy lifestyle construct consists of the dimensions of 'physical participation', 'nutritional habits', 'health awareness' and 'safety practices'; and the psychosocial construct consists of the dimensions of 'stress management', 'identity awareness' and 'social support'. For example, item No. 1 is 'Discuss my problems and concerns with people close to me'.

BMI and weight measurement: Standard anthropometric measurements include weight, height, Body Mass Index (BMI) and blood pressure. BMI is determined by dividing body weight in kilograms by height in meters squared $\left(\mathrm{kg} / \mathrm{m}^{2}\right)$ according to genderand age-specific growth charts produced by the Centers for Disease Control [21]. Students with a BMI equal to or greater than the $85^{\text {th }}$ percentile were classified as overweight.

Body Shape Scale: Using the Body Shape Scale, this study asked the adolescents to rate their current body shape, with 1 indicating poor, 2 average, 3 good, and 4 excellent [22]. There are nine body shapes rating on the Scale. The present study suggests that their self-efficacy beliefs determine this body shape rating.

\section{Statistical analysis}

This was a quasi-experimental study design with a control group and pre- and post-tests. The paired $t$-test with repeated measures and Chisquared test were used for testing the impact of the efficacy-enhancing weight management program on appropriate eating and exercising. The Statistical Package for the Social Sciences (SPSS) software version 17.0 for Windows was used. As a measure of internal consistency,

Cronbach's alpha was computed for the Chinese versions of WEL, NES, PES, SES, ALQ and body shape. A $t$-test was conducted using time as a repeated measures factor, gender as a between-subjects factor and eating behaviours and psychological characteristics as dependent variables. The mean proportions of adolescents with increased selfefficacy scores were compared between the control and intervention groups. A t-test was performed to compare both groups. All data are expressed as mean \pm SD or $n(\%)$ where appropriate. Chi-squared and $t$-test were used to identify gender and group differences. A previous study was done in Chinese adolescents, with a standard deviation for the school level proportion of schoolchildren increasing 0.78 [23]. The study was sufficiently powered (over $84 \%$ ) to detect a difference between the control and intervention groups assuming the given standard deviation. The pre- and post-tests that compared the differences between the two groups using paired $t$-test and two-sided $p$-value $<0.05$ (2-tailed) were considered statistically significant.

Ethical approval was obtained from the University Research Ethics Committee and the studied primary schools prior to commencement of the study. A letter was sent by the principals to all parents of the recruited P.4-6 primary school students in two groups, stating the purpose of the study and giving them an assurance of confidentiality. Parents were requested to sign a consent form to give consent for their adolescents in Primary 4, 5 and 6 (aged 10-13) to participate in the study.

\section{Results}

\section{Characteristics of study participants}

Four primary schools with 119 overweight and obese (mean BMI $36.21 \mathrm{~kg} / \mathrm{m}^{2}$ ) adolescents aged 10-13 enrolled in levels P.4-6 agreed to participate and were assigned to either the intervention ( $\mathrm{n}=59$ students) or control group ( $\mathrm{n}=60$ students). The demographic characteristics of the 119 overweight and obese adolescents (mean BMI $24.35 \mathrm{~kg} / \mathrm{m}^{2}$ ) are shown in table 1 . There were 79 boys (66.7\%) and 40 girls (33.3\%) aged 10-13. They were assigned to two groups, an intervention group $(\mathrm{n}=60,42$ boys $(70.0 \%)$ and 18 girls $(30.0 \%)$ with a mean age of 10.44 years $(\mathrm{SD}=0.99))$ and a control group $(\mathrm{n}=60,38$ boys $(63.3 \%)$ and 22 girls $(36.7 \%)$ with a mean age of 11.43 years $(\mathrm{SD}=1.02))$. Almost all the families $(n=51,86.5 \%)$ were living in public subsidised housing with monthly family incomes ranging from $\mathrm{HK} \$ 5,000$ to $\$ 14,999$, and thus represented the low to middle socio-economic class in Hong Kong.

\section{Efficacy-enhancing weight management intervention}

The main short-term effects regarding the efficacy-enhancing weight management intervention can be found in table 2 . This study reported intermediate behavioural and physiological measures in addition to weight outcomes. The mean BMI for the intervention group decreased from the pre-test $(M=25.09, S D=3.84)$ to the post-test $(\mathrm{M}=24.44, \mathrm{SD}=3.78)$, as shown in table 2, whereas for the control group it increased from the pre-test $(\mathrm{M}=24.25, \mathrm{SD}=3.08)$ to the post-test $(\mathrm{M}=24.50, \mathrm{SD}=2.72)$ as shown in table 2 . Increases in all self-efficacy scores and decreases in weight were seen in the BMI measures at six months for the intervention group, primarily from stabilizing BMI in those receiving the self-efficacy interventions. The results of this study showed that overweight and obese adolescents in the control group scored lower on all the self-efficacy measures compared with overweight and obese adolescents in the intervention group.

Self-efficacy scores: The intervention group demonstrated shortterm effects in all the self-efficacy scores. Their net increases in selfefficacy scores from baseline to 6 months were 0.67 for WEL ( $p=0.62$ ), 0.58 for NES ( $p=0.27$ ) and 0.75 for PSE ( $p=0.20)$, as shown in table 2 . The cognitive capabilities of adolescents in the intervention group increased in relation to nutrition, physical activity and social pressure with the implementation of a self-regulatory weight management program. The results of this study support those of previous work, which found that the WELQ, NES and PES could be used to assess changes in self-efficacy in relation to food and physical activity arising from participating in a self-regulatory (brief behaviour modification) weight management program [16,17].

Change in BMI: After an intensive 6-month behavioral (efficacy- 
Citation: Regina Lee LT, Loke AY (2013) A Quasi-Experimental Intervention to Improve Self-Efficacy for Eating and Exercise Weight Management: Short-Term Effects. J Nutr Disorders Ther 3:121. doi:10.4172/2161-0509.1000121

Page 5 of 7

\begin{tabular}{|c|c|c|c|c|c|c|c|}
\hline \multirow[t]{2}{*}{ Variables } & \multirow[t]{2}{*}{ Items } & \multicolumn{2}{|c|}{ Intervention Group $(n=59)$} & \multicolumn{2}{|c|}{ Control Group $(n=60)$} & \multirow[b]{2}{*}{$x^{2}$} & \multirow[b]{2}{*}{$p$} \\
\hline & & $\mathrm{n}$ & $\%$ & $\mathrm{n}$ & $\%$ & & \\
\hline \multicolumn{8}{|l|}{ Gender } \\
\hline & Boys & 42 & 71.2 & 37 & 61.4 & & \\
\hline & Girls & 17 & 28.8 & 23 & 38.3 & & \\
\hline & Total & 59 & 100.0 & 60 & 100.0 & 1.208 & 0.272 \\
\hline \multicolumn{8}{|l|}{ Age } \\
\hline & $\leq 10$ & 19 & 32.2 & 12 & 20.0 & & \\
\hline & 11 & 26 & 44.1 & 21 & 35.0 & & \\
\hline & 12 & 11 & 18.6 & 17 & 28.3 & & \\
\hline & $\geq 13$ & 3 & 5.1 & 10 & 16.7 & & \\
\hline & Total & 59 & 100.0 & 60 & 100.0 & 12.575 & 0.051 \\
\hline \multicolumn{8}{|c|}{ Father's education level } \\
\hline & Primary or below & 23 & 39.0 & 17 & 28.3 & & \\
\hline & Secondary & 36 & 61.0 & 39 & 65.0 & & \\
\hline & University or above & 1 & 1.7 & 4 & 6.7 & & \\
\hline & Total & 59 & 100.0 & 60 & 100.0 & 2.820 & 0.244 \\
\hline \multicolumn{8}{|c|}{ Mother's education level } \\
\hline & Primary or below & 19 & 32.2 & 19 & 16.7 & & \\
\hline & Secondary & 39 & 66.1 & 36 & 58.3 & & \\
\hline & University or above & 1 & 1.7 & 5 & 8.3 & & \\
\hline & Total & 59 & 100.0 & 60 & 100.0 & 2.877 & 0.237 \\
\hline \multicolumn{8}{|c|}{$\begin{array}{l}\text { Family income (per } \\
\text { month) }\end{array}$} \\
\hline & $\leq 9999$ & 29 & 49.2 & 17 & 50.0 & & \\
\hline & $10000-19999$ & 23 & 39.0 & 15 & 41.7 & & \\
\hline & $\geq 20000$ & 7 & 11.9 & 10 & 8.3 & & \\
\hline & Total & 59 & 100.0 & 60 & 100.0 & 0.371 & 0.831 \\
\hline
\end{tabular}

Table 1: Characteristics of boys and girls in the intervention and control groups $(\mathrm{N}=119)$.

\begin{tabular}{|c|c|c|c|c|c|c|c|c|c|c|}
\hline & \multicolumn{2}{|c|}{ Intervention Group $(n=59)$} & & & \multicolumn{2}{|c|}{ Control Group } & & & \multirow[b]{2}{*}{$t$-test } & \multirow[b]{2}{*}{$p$-value } \\
\hline & \multirow{2}{*}{$\begin{array}{c}\text { Pre-intervention } \\
\text { Mean } \pm \mathrm{SD}\end{array}$} & \multirow{2}{*}{$\begin{array}{c}\text { Post-intervention } \\
\text { Mean } \pm \mathrm{SD}\end{array}$} & & & Pre-test & Post-test & & & & \\
\hline Variables & & & Paired $t$-test & $p$-value & Mean \pm SD & Mean \pm SD & Paired t-test & $p$-value & & \\
\hline Age (year) & $10.44 \pm 0.99$ & - & -0.656 & 0.513 & $11.17 \pm 1.12$ & - & -1.317 & 0.190 & -3.12 & $0.002^{*}$ \\
\hline $\mathrm{BMl}^{\mathrm{a}}(\mathrm{cm})$ & $25.09 \pm 3.84$ & $24.44 \pm 3.78$ & 0.285 & 0.776 & $24.25 \pm 3.08$ & $24.50 \pm 2.72$ & -0.448 & 0.655 & 0.230 & 0.819 \\
\hline Weight(kg) & $53.15 \pm 12.03$ & $53.10 \pm 11.85$ & -0.545 & 0.586 & $54.20 \pm 10.95$ & $56.38 \pm 0.41$ & -1.27 & 0.206 & -1.27 & 0.206 \\
\hline Weight loss (kg) & - & $-0.05 \pm 0.61$ & - & - & - & $+2.18 \pm 2.93$ & - & - & - & - \\
\hline WEL'b score & $24.58 \pm 6.94$ & $25.25 \pm 8.12$ & -0.487 & 0.627 & $26.05 \pm 7.37$ & $25.90 \pm 8.74$ & 0.102 & 0.919 & -0.417 & 0.677 \\
\hline NES ${ }^{c}$ score & $8.95 \pm 2.37$ & $9.53 \pm 3.27$ & -1.096 & 0.275 & $9.57 \pm 2.91$ & $8.90 \pm 3.17$ & 1.200 & 0.232 & 1.060 & 0.291 \\
\hline PSE $^{\mathrm{d}}$ score & $6.96 \pm 2.70$ & $7.71 \pm 3.64$ & -1.264 & 0.209 & $8.30 \pm 3.67$ & $7.27 \pm 3.32$ & 1.618 & 0.108 & 0.698 & 0.487 \\
\hline SES $^{\mathrm{e}}$ score & $35.44 \pm 6.99$ & $40.41 \pm 9.85$ & -3.158 & $0.002^{*}$ & $39.86 \pm 11.09$ & $42.15 \pm 11.54$ & -1.101 & 0.273 & -0.885 & 0.387 \\
\hline ALQ ${ }^{f}$ score & $75.67 \pm 19.50$ & $78.71 \pm 25.19$ & -0.732 & 0.466 & $84.93 \pm 21.07$ & $81.30 \pm 22.4$ & 0.914 & 0.362 & -0.592 & 0.555 \\
\hline $\mathrm{BS}^{9}$ score & $2.76 \pm 0.89$ & $3.08 \pm 0.88$ & -1.994 & $0.048^{*}$ & $2.97 \pm 1.09$ & $2.90 \pm 0.95$ & 0.348 & 0.729 & 1.101 & 0.273 \\
\hline
\end{tabular}

* $p \leq 0.050$ aBMI: body mass index. ${ }^{b} W E L$ : Weight Self-Efficacy Lifestyle. ${ }^{c N E S}$ : Nutrition Self-Efficacy Scale.

dPES: Physical Exercise Self-Efficacy Scale. eSES: Self-Esteem Scale.

${ }^{f} A L Q$ : Adolescent Lifestyle Questionnaire. ${ }^{g B S}$ : Body Shape.

Table 2: Within-subject changes and distributions of changes in self-efficacy, self-esteem, lifestyle, body shape, weight measures and $\mathrm{BMI}(\mathrm{N}=119$ ).

enhancing) weight management program, the comprehensive behavioral intervention resulted in statistically significant differences in weight and BMI from baseline to 6 months, due largely to the prevention of weight or BMI gain in the intervention group as shown in table 2 .

Self-Esteem: The intervention affected self-esteem through its impacts on participants' self-efficacy beliefs in eating appropriately and intention to exercise regularly. Thus, this intervention treatment had overall positive impacts, including the most significant impact on adolescents' self-esteem after the intervention $(t=3.2, \mathrm{p}=0.002)$ using the $t$-test between the pre- and post-tests in the intervention group; whereas there was no statistical significant difference in the self-esteem of the control group $(\mathrm{p}=0.273)$.

Lifestyle behaviours: Although there was no significant difference in lifestyle behaviors between the two groups, the mean score increased by 3.04 in the intervention group. The mean score for lifestyle behaviours decreased by 3.63 in the control group.

Body shape: The intervention group achieved a slight weight loss from baseline to post-treatment $(-0.05 \mathrm{~kg} \pm 0.61)$ compared with the control group $(+2.18 \mathrm{~kg} \pm 2.93 ; \mathrm{t}=-1.27 ; \mathrm{p}=0.21)$. The intervention group perceived a greater change in body shape from baseline to posttreatment for the self-judgment of good or excellent (from 57.6\% to 
$78.0 \%$ ) versus for the self-judgment of bad (from $42.4 \%$ to $22.0 \%$ ). For the control group, the self-judgment of good or excellent body shape increased from $62.7 \%$ to just $67.8 \%$ from baseline to post-treatment, and there was no change in the self-judgment of bad body shape.

Reach of intervention: Table 2 shows the reach of the intervention in the short term among baseline overweight and obese adolescents in the post-test of the intervention group. Self-efficacy scores increased over time among adolescents in the intervention group, ranging from 0.58 to 0.75 , but decreased among those in the control group with the range from -0.15 to -1.03 . Self-efficacy beliefs for physical activity explained the 0.45 total indirect effect of the weight management program on BMI change.

This study examined the short-term effect and key learning from the planned efficacy-enhancing weight management program. These results were in line with the objectives of the study. Lessons were learned on how to develop relevant, focused programs that are lowcost, sustainable and scalable. The programs were evaluated for their acceptability, feasibility and evidence of benefit. Found to be low-cost and acceptable, the program (intervention) reached both vulnerable obese and overweight students and those with low household incomes. It was well received; with high attendance levels (over $90 \%$ of participants attended all planned activities). In addition, typical evaluations given by the participating adolescents in a support meeting included "I liked the program", "The program was useful", and "I felt very good after I had lost some weight and could put those pants back on". In the area of feasibility, the planned program was able to recruit successfully $(90 \%$ of the target).

\section{Discussion}

This study reported intermediate behavioural measures, including measuring changes in eating behaviours, physical activity and sedentary behaviours, in addition to weight outcomes. These outcomes were more common in recent research [10]. In this study, most adolescents $(n=50$, $80 \%)$ in the intervention group reported reductions in weight after attending the efficacy-enhancing weight management interventions. The results were also consistent with another follow-up study in Finland [24]. They provide public health workers with a better understanding of how social cognitive theory can guide the weight loss program in motivating, supporting and reinforcing adolescents' healthy lifestyle practices.

In this study, self-efficacy has been found to be a significant predictor of weight loss, confirming the value of assessing weight-control selfefficacy in obese adolescents seeking weight loss interventions. Other studies have also assessed the potential influences of self-efficacy in motivating obese individuals to initiate behavior change by adopting healthy lifestyle behaviors [25-27]. They also found that interventions that improve self-efficacy help participants to lose more weight during the intervention.

The results of this study indicate that the targeted behaviors had been reinforced by special recognition activities and items involving participation in challenges and competitions. The self-regulatory interventions for overweight and obese adolescents were designed to improve their self-efficacy and self-competence via interactive activities such as games and role play, as positive self-efficacy and self-competence could promote internal motivation to change health behaviors and maintain a healthy weight for the intervention components [28]. The results suggest that a self-monitoring campaign must be designed to coordinate with the curriculum of classroom activity, health education and nutrition in order to change target behavior. Two levels of behavior were evaluated: individual and group. For individual evaluation, adolescents had to self-evaluate their behavior at the baseline assessment (Semester I - September-January 2009) and then set a personal goal for behavior change. Adolescents who achieved their behavioral change according to their personal goals were rewarded. The use of self-determination theory-based interventions with motivational interviewing in a multidisciplinary weight management program has been a remarkable step forward in the field of action to promote healthy lifestyles in weight reduction [29].

\section{Strengths and limitations}

The study recruited a small sample (119 participants) that targeted the overweight and obese to examine cognitive behavioural modification interventions over a relatively short period of time. The interpretation of the results is restricted by the selection of a convenience sample of overweight and obese adolescents in four primary schools in one of the 18 districts in Hong Kong, which does not allow for a more complete representation of the population. The study aimed to examine the effect of the weight loss interventions for only 6 months, and longitudinal studies are needed to evaluate the sustainability of the outcomes. Adolescents' self-reported measures might have led to potential bias. The key measures in this study have been translated into Chinese and tested for validity in a study in Hong Kong. Other factors, such as parental involvement and support, are key indicators of the success of weight reduction programs among adolescents. Parents and schools should offer affordable options and support for adolescents to be physically active.

\section{Conclusion}

This study evaluated the effect of a self-regulatory weight loss intervention using a self-efficacy approach for overweight and obese adolescents. The intervention was effective. The study demonstrated that the efficacy-enhancing weight management intervention program helped overweight and obese adolescents to reach their goals because the intervention group was motivated and participants felt that they were capable of achieving their pre-set goals and striving for those behaviours via the cognitive enhancing strategies of learning from each other and sharing their feelings, experiences and support. Public health workers can use cognitive social theory to plan programs for high-risk groups of adolescents with special health needs, such as overweight and obese schoolchildren and adolescents. Future research is needed to follow up on the sustainability of the changed behaviours in the intervention group.

\section{Acknowledgement}

The author would like to thank the adolescents, their parents, and the involved school teachers from the four participating primary schools, for their contribution to the success of this study.

\section{References}

1. World Health Organization (2011) Global status report on non-communicable diseases 2010.

2. Gillison FB, Standage M, Skevington SM (2006) Relationships among adolescents' weight perceptions, exercise goals, exercise motivation, quality of life and leisure-time exercise behaviour: a self-determination theory approach. Health Educ Res 21: 836-847.

3. Seagle HM, Strain GW, Makris A, Reeves RS, American Dietetic Association (2009) Position of the American Dietetic Association: weight management. J Am Diet Assoc 109: 330-346.

4. Baudura A (1986) Social foundations of thought and action: a social cognitive theory. Englewood Cliffs, NJ: Prentice-Hall,US

5. Biddle SJH, Hagger MS, Chatzisarantis NLD, Lippke S (2007) Theoretica 
Citation: Regina Lee LT, Loke AY (2013) A Quasi-Experimental Intervention to Improve Self-Efficacy for Eating and Exercise Weight Management: Short-Term Effects. J Nutr Disorders Ther 3:121. doi:10.4172/2161-0509.1000121

Page 7 of 7

frameworks in exercise psychology. In: Tenenbaum $\mathrm{G}$ and Eklund RC (eds.). Handbook of Sport Psychology. Hoboken: NJ: John Wiley, 537-559.

6. Lewis BA, Marcus BH, Pate RR, Dunn AL (2002) Psychosocial mediators of physical activity behavior among adults and children. Am J Prev Med 23: 26-35.

7. Dennis KE, Goldberg AP (1996) Weight control self-efficacy types and transitions affect weight-loss outcomes in obese women. Addict Behav 21 : 103-116.

8. Martin PD, Dutton GR, Brantley PJ (2004) Self-efficacy as a predictor of weight change in African-American women. Obes Res 12: 646-651.

9. Williams DM, Anderson ES, Winett RA (2005) A review of the outcome expectancy construct in physical activity research. Ann Behav Med 29: 70-79.

10. Irby M, Kaplan S, Garner-Edwards D, Kolbash S, Skelton JA (2010) Motivational interviewing in a family-based pediatric obesity program: a case study. Fam Syst Health 28: 236-246.

11. Miller WR, Rollnick S (2012) Meeting in the middle: motivational interviewing and self-determination theory. Int J Behav Nutr Phys Act 9: 25.

12. Baranowski T, Cooper DM, Harrell J, Hirst K, Kaufman FR, et al. (2006) Presence of diabetes risk factors in a large U.S. eighth-grade cohort. Diabetes Care 29: 212-217.

13. Speiser PW, Rudolf MC, Anhalt H, Camacho-Hubner C, Chiarelli F, et al. (2005) Childhood obesity. J Clin Endocrinol Metab 90: 1871-1887.

14. Weiss R, Caprio S (2005) The metabolic consequences of childhood obesity. Best Pract Res Clin Endocrinol Metab 19: 405-419.

15. Foster C, Hillsdon M (2004) Changing the environment to promote healthenhancing physical activity. J Sports Sci 22: 755-769.

16. Bandura A (1977) Self-efficacy: toward a unifying theory of behavioral change. Psychol Rev 84: 191-215.

17. Clark MM, Abrams DB, Niaura RS, Eaton CA, Rossi JS (1991) Self-efficacy in weight management. J Consult Clin Psychol 59: 739-744.

18. http://userpage.fu-berlin.de/health/healself.pdf
19. Rosenberg N (1965) Society and the Adolescent Self-Image. NJ: Princeton University Press.Prinston, USA.

20. Lee RL, Loke AY, Wu CS, Ho AP (2010) The lifestyle behaviours and psychosocial well-being of primary school students in Hong Kong. J Clin Nurs 19: $1462-1472$.

21. http://www.cdc.gov/growthcharts/html_charts/bmiagerev.htm22.

22. Lerner RM, Jovanovic $J$ (1990) The role of body image in psychosocial development across the life span: A developmental contextual perspective. In Cash TF, Pruzinsky T (Eds.), Body images: Development, deviance, and change (316-333). New York: Guilford Press.

23. Chinese University of Hong Kong. Report on school-based weight management programme for children. Center for Health Education and Health Promotion School of Public Health and Primary Care, Faculty of Medicine, Hong Kong, 2008

24. Rautio N, Jokelainen J, Oksa H, Saaristo T, Peltonen M, et al. (2011) Socioeconomic position and effectiveness of lifestyle intervention in prevention of type 2 diabetes: one-year follow-up of the FIN-D2D project. Scan Journal of Public Health 39:561-570.

25. Dishman RK, Motl RW, Sallis JF, Dunn AL, Birnbaum AS, et al. (2005) Selfmanagement strategies mediate self-efficacy and physical activity. Am J Prev Med 29: 10-18.

26. Silva MN, Markland D, Minderico CS, Vieira PN, Castro MM, et al. (2008) A randomized controlled trial to evaluate self-determination theory for exercise adherence and weight control: rationale and intervention description. BMC Public Health 8: 234

27. Annesi JJ, Gorjala S (2010) Relations of self-regulation and self-efficacy fo exercise and eating and BMI change: A field investigation. Biopsychosoc Med 4: 10 .

28. Baranowski T, Anderson C, Carmack C (1998) Mediating variable framework in physical activity interventions. How are we doing? How might we do better? Am J Prev Med 15: 266-297.

29. Rothman AJ, Baldwin A, Hertel A (2004) Self regulation and behavior change: disentangling behavioral initiation and behavioral maintenance. In: Vohs KD, Baumeister RF (eds.). Handbook of New York, NY: Guilford,130-148. 